\title{
Negotiating growth of online education in higher education
}

\author{
Neil P. Morris ${ }^{1 *}$ (D, Mariya Ivancheva ${ }^{2}$, Taryn Coop ${ }^{1}$, Rada Mogliacci ${ }^{3}$ and Bronwen Swinnerton ${ }^{1}$
}

\author{
* Correspondence: n.p.morris@leeds. \\ ac.uk \\ ${ }^{1}$ School of Education, University of \\ Leeds, Leeds, UK \\ Full list of author information is \\ available at the end of the article
}

\begin{abstract}
Universities are facing growing internal and external pressures to generate income, educate a widening continuum of learners, and make effective use of digital technologies. One response has been growth of online education, catalysed by Massive Open Online Courses, availability of digital devices and technologies, and notions of borderless global education. In growing online education, learning and teaching provision has become increasingly disaggregated, and universities are partnering with a range of private companies to reach new learners, and commercialise educational provision. In this paper, we explore the competing drivers which impact decision making within English universities and their strategies to grow online education provision, through interviews with senior managers, and interrogation of their views through the lens of a range of internal, external and organisational drivers. We show that pressures facing universities may be alleviated by growth of online education provision, but that negotiating an appropriate route to realise this ambition involves attempts to resolve these underlying tensions deriving from competing drivers. We use a modified form of the PEST model to demonstrate the complexities, inter-dependencies and processes associated with these drivers when negotiating delivery of unbundled online education through use of private company services, or in partnership with private companies.
\end{abstract}

Keywords: Higher education, Digital technology, Marketisation, Unbundling, Online programme management companies

\section{Introduction}

This article discusses the factors influencing how universities in England are negotiating the growth of online education provision, specifically that which is disaggregated, or unbundled, and offered via online learning platforms. We explore how public universities are engaging with private companies operating in this space, and try to uncover the drivers of change impacting decision-making, and how these often competing drivers reveal underlying tensions. We build on previous work related to the role of the market in higher education by exploring the practical management of relationships with private companies and their role in unbundling at the micro-level of strategic decision-making by individuals. This unique study analyses interview data with senior managers in four public universities in England using a modified PEST

(c) The Author(s). 2020 Open Access This article is licensed under a Creative Commons Attribution 4.0 International License, which permits use, sharing, adaptation, distribution and reproduction in any medium or format, as long as you give appropriate credit to the original author(s) and the source, provide a link to the Creative Commons licence, and indicate if changes were made. The images or other third party material in this article are included in the article's Creative Commons licence, unless indicated otherwise in a credit line to the material. If material is not included in the article's Creative Commons licence and your intended use is not permitted by statutory regulation or exceeds the permitted use, you will need to obtain permission directly from the copyright holder. To view a copy of this licence, visit http://creativecommons.org/licenses/by/4.0/. 
model to uncover how they perceive, and respond to, the new boundaries between public and private in the online education space, and how their strategies vary depending on context, their organisational culture and their mission. This paper contributes to our understanding of the tensions at play in higher education by exploring the factors driving the growth in online provision and their impact on strategic decision-making.

\section{Growth of online education}

The unbundling of higher education learning and teaching provision has been based on two coexisting, yet increasingly conflicting rationales: allowing mass access to education (pushing the priorities towards the public) and marketisation (drawing the sector closer to the interest of the free market). The notion of open mass access has been accelerated by the emergence of digital technologies that enabled the global rise of an Open Educational Resources movement and the provision of online education through digital platforms (Alevizou, 2015; Deem, Hillyard, \& Reed, 2007; McNay, 2005). Many universities offer their educational provision online to learners globally, either using internal systems (e.g. virtual learning environments (VLEs) or learning management systems) or using online learning platforms owned by private companies (e.g. Coursera, EdX, FutureLearn). This provision may be in the form of full degree programmes, creditbearing short courses or Massive Open Online Courses (MOOCs), with provision being unbundled. Unbundling has been discussed as a process that signalled "the end of the university as we know it" (McCowan, 2017: 3). The concept of unbundling, originally referring to organisational changes in software and law, has recently entered higher education studies and policy discourse (Komljenovic \& Robertson, 2016), initially affecting quality assurance, research, infrastructure, and leisure facilities (Craig, 2015). Disaggregation of the traditional university 'bundle' has grown to affect other domains such as administration and management (Komljenovic \& Robertson, 2016). Nowadays private companies are increasingly covering different functions also related to the core business of the university: curriculum development, module delivery, student evaluation, and the awarding of credentials (Wallhaus, 2000: 22). Unbundling in higher education has been seen as offering 'no-frills' cheaper education and mix-and-match content options. While the former has been compared to Ryanair low-budget flights (Galbraith, 2018), the latter has been envisaged as 'student playlists': "[a] llowing students to pick and choose individual courses from leading experts at a range of universities, accrediting these to validate a degree" (McIntosh, 2018: 1) We define unbundling as the 'disaggregation of educational provision into its component parts, likely for delivery by multiple stakeholders, often using digital approaches' (Swinnerton et al., 2019). An example of unbundled educational provision could be a degree programme offered as individual standalone modules available for credit via an online platform, to be studied at the learners' pace, in any order, on a pay-per-module model.

\section{The influence of the market on public universities}

Providing online education to learners globally can be an expensive, highly skilled and complex venture. The reduction in state funding of higher education globally not only increases the need for new revenue streams, it also reduces universities' ability to spend large amounts in potentially risky investment in digital platforms and highly skilled 
development teams. Delivery of online education (either full degrees, or unbundled components) commonly involves public universities partnering with, or using the services of, private companies (mainly referred to as Online Program Management providers or 'OPMs'), or online platform providers (see Hill, 2017), who are willing to invest and shoulder risk in return for a stake in this expanding market and future profit. The discussion of a public-private divide has been central to higher education studies. Focusing on teaching and learning, unbundling and provision of online education is challenging the notions of the core mission of the university (Swartz, Ivancheva, Morris, \& Czerniewicz, 2018). Combining economic and political approaches to the discussion of higher education as a public good, Marginson (2018) discusses four different constellations in which the market can function: civil society, where teaching is carried out by actors outside the university and is for the public good; state-quazi market in which educational provision is a quazi commodity which is limited to a few; a pure market situation under which teaching is a pure commodity that has a market value and private gain for individuals; and social democracy conjuncture in which a nation state intervenes to regulate provision and make it available for many (Marginson, 2018). Komljenovic and Robertson (2016) identified market exchanges that involve the university both as a buyer and seller of services with exchanges and services being either for- or not-for profit, pointing to the diversity of types of markets and goods that are involved when considering what is meant by marketisation. Over the last three decades, there has been an increasing pressure - both economic and political - to orient all higher education efforts into the pure market situation. Since deregulating the market to invite private providers, UK university education has increasingly been seen through the narratives of 'value for money' and 'employability', presenting students as consumers, and education as a commodity for private benefit (Boden \& Nedeva, 2010; Tomlinson, 2018). The increasing role of private providers in the provision of online learning, as partners with universities, is another manifestation of this phenomenon. Yet what this means for the English higher education system, where it stands, and how it shifts in the public-private dichotomy as a result of unbundling, remains an open question.

\section{Unbundling: digital disruption and drivers of change}

Unbundling came through a grass-roots civil-society push to address mass access to higher education through emphasis on personalisation, flexibility, and low-cost options that could accommodate students whose entry was jeopardised by market pressures (Alevizou, 2015). However, unbundling has been affected and affects at equal measure the renegotiation of the public-private divide in higher education with the increase of private providers around the university sector, the push for metric-driven excellence attracting fee-paying international students, and the requirement to produce graduates contributing to economic growth. In an increasing global competition for attracting fee-paying students and grants, universities are under pressure to diversify their funding base through tuition and business partnerships (Streckeisen, 2018: 52). With consecutive UK governments introducing new public management and market mechanisms into the public sector (Robertson, 2010), private universities and subcontractors for services not related directly to education have entered the higher education terrain, 
including OPMs and online platform providers (Robertson \& Komljenovic, 2016). With growing acceptance of online degrees globally (e.g. India (Sanzgiri, 2017); New Zealand (Lewis, 2015)), UK universities have used their strategic positions to tap into this market, to realise return on investment for real estate development and digital technology investments made for campus- and online-learning. In time of budget cuts, whereby the core budget of public universities comes from student fees, and research is sponsored through competitive external (if public) funding (Robertson, 2010; Swartz et al., 2018), universities see in online learning two interrelated advantages: additional income, from a new student population not requiring as much space as campus-based learners; and the possibility to reuse and rebundle content. However, institutions with varying missions, teaching-research focus, and organisational culture, have taken different approaches to online education growth and partnerships, as have the private companies looking for partnerships (Swinnerton et al., 2019).

As more previously 'atypical' student populations access higher education - women, working class students, ethnic minorities, mature students, international students and people with disabilities - shorter, more flexible, bite size 'pay-as-you-go' learning opportunities and qualifications are in growing demand (Gorard et al., 2006). The growing ubiquity of devices, technology and familiarity with online learning is shared by the millennial generation (Jones \& Shao, 2011) or at least by an educated sub-group within it. Since the advent of MOOCs, despite the partial compromise of its full openness, there has been a steady and significant growth and diversity in MOOC learners (Morris, Swinnerton, \& Hotchkiss, 2015). This has meant the diversification of MOOC platforms, growing convergence of OPMs and MOOC platform providers, and growth of alternative online providers (Hill, 2017). Educators have seen online and blended learning options as an add-on to face-to-face pedagogic work through innovative teaching, rather than full replacement of campus-based learning (Redmond, 2011). Physical campuses are constrained in their ability to grow and accommodate the steady increase of undergraduate and postgraduate students (Croft, Dalton, \& Grant, 2010; UUK, 2017: 8) and increasingly unfit for new pedagogic approaches, but expensive to upgrade (Glance, 2014). Growing concerns about climate change make online education a potentially lower-carbon, paper-less sustainable solution (Fawcett, 2005), yet educators still need to balance benefits that come from campus experience. Increasingly, educators are moving toward student-centred learning, encouraging an inclusive and flexible curriculum, focused on active, skills- and problem-solving based education (see Coleman \& Money, 2019). Challenged as individualistic (Munro, 2018), this approach reflects both an ideological shift of thinking of education in a narrow market framework as benefiting individual student needs (Marginson, 2018) and to changes in the fee structure and new demands of the job market to universities to produce readily trained 'employable' students (Boden \& Nedeva, 2010). Yet, it is also a response to new philosophical paradigms in education that present knowledge as available everywhere rather than just within elite universities. Against this background, the new affordances of digital technologies are both an opportunity and a challenge (Selwyn, 2014). By allowing the best of campus-based blended learning education in an online environment using a variety of learning theories (Drumm, 2019), educators are pushed to respond to demands for flexibility, personalisation, and adaptability to the job market necessary for students (Baykan, 2017). 
The multiplicity of factors driving change and the associated challenges being faced by public universities in England to which unbundling teaching and learning via digital approaches through public-private partnerships may or may not offer possible solutions are clear. McCowan has suggested that despite this process effecting profound changes in the notion of the university, more empirical research and broader theoretical analysis on unbundling are still lacking (McCowan, 2017). To address this gap, we follow work identifying unbundling in higher education as a process of market-making (Komljenovic \& Robertson, 2016; Robertson \& Komljenovic, 2016) and views that macro analyses should be accompanied with "micro analysis of the practical, material, technical and discursive effort of market-making and maintenance" (Williamson, 2018). There is still little research discussing how decision-making on unbundling is negotiated, insisted on or resisted by different groups engaged in this process within the university community. This study is an attempt to fill that gap.

\section{Decision making in organisations}

The starting position for our research is in the technology adoption literature, where Roger's Diffusion of Innovation model described the agents and mechanisms of change in organisations, according to categorisations of stakeholders (Rogers, 1995). This model has evolved and been used in many contexts, and has given rise to a large literature in management studies about strategic decision-making processes in organisations (CIPD, 2018). Traditional models have focused on the PEST model, where external political, environmental, societal and technological drivers are considered as factors influencing decision making. This taxonomy has been used many times in organisational settings, and has evolved to include other factors (e.g. ethical, legal, economic) which created the 'STEEPLE' acronym and other similar models (Burt, Wright, Bradfield, Cairns, \& Van Der Heijden, 2014). Although these models have been used successfully by organisations, they are criticised for lack of appreciation of context, interdependencies between factors, innovation, rationality and forward planning activities such as scenario planning (Burt et al., 2014). Research studies exploring strategic decision making in higher education have used a variety of models to conceptualise how senior leaders arrive at decisions, including use of PEST models, technology adoption models (Kirkwood \& Price, 2016), socio-cultural and structural context (Englund, Olofsson, \& Price, 2018) and cultural-historical activity theory (Cliff, Walji, Mogliacci, Morris, \& Ivancheva, 2020). Scholars have also considered both internal and external factors impacting on decision-making, including the impact of organisation, organisational culture, organisational mission and brand and management approach. A recent study by Fumasoli, Barbato, and Turri (2019) showed through an extensive literature review that 'two theoretical frameworks are mostly used: the environmental determinism perspective and the managerial rationality approach' to account for how universities position themselves, and suggest that 'organisational structure, identity and centrality' forms the bridge between the external and internal drivers (Fumasoli et al., 2019). Here, we have chosen to use a modified form of the PEST model (which takes into consideration the recent literature about the need to consider external and internal drivers, context, organisational factors and inter-dependences between these) as an analytical tool to categorise and synthesise factors which drive decision making in 
universities in relation to scaling up online education. This approach allows us to uncover the contradictions and tensions experienced by decision makers as a result of the impact of these drivers.

We now explore how these complex processes are perceived by senior managers engaged with teaching and learning within universities with varying missions within the UK, examining their perspectives analytically through the lens of a range of external and internal drivers of change. On the basis of their narratives, we outline some of the contradictions and tensions in navigating the potentials and perils of unbundling for the future of the university within a shifting public-private terrain. Our research question is as follows: What are the key drivers of change affecting decision-making about growth of online education in universities in England?

\section{Methodology}

\section{Sample}

This paper draws on eight qualitative interviews with senior decision makers across four public universities in England: two Russell Group (University $A$ and $B$ ) and two post-1992 institutions (University $X$ and $Y$ ). Russell Group universities are representatives of a UK university membership group with a global reputation for academic achievement and a focus on research, while post-1992 are former polytechnics that are more teaching-intensive and with greater connection to local industries and communities. All four universities use blended learning approaches through VLEs, and offer some access to digital devices and Internet for students. Initial desk research, consisting of website searches (institutions and private companies), press releases and telephone calls to institutions, was used to characterise all UK universities by their membership group and activities in online education, involving private partners or not. These four institutions were purposefully selected to offer a representative sample of UK universities of different types, engaged in online education using different mechanisms and approaches, as described below:

- University $A$ had a partnership with an OPM working with online degrees, and multiple partnerships with online platform providers to deliver MOOCs, short courses, and full online degrees.

- University $B$ had a single partnership with an OPM working with online degrees only, and a partnership with an online platform provider for MOOCs;

- University $X$ engaged in partnerships both offering MOOCs and full online degrees;

- University $Y$ had no declared partnerships with OPMs, but partnered with a private company to support distance learning.

The interviewees all held senior management roles within their institutions (e.g. ProVice Chancellor, Director of Learning and Teaching, Director of Online Learning etc.), and were responsible for the organisation of online and blended modes of teaching and learning within each of these respective institutions. Where the institution also had a partnership with an OPM provider, the interviewee was the senior manager responsible for managing that partnership. All participants signed an informed consent form, and were made aware of the ethical clearance of the project obtained at our own and their 
respective institutions, as well as being assured that their interview would be fully anonymised and their role and institution de-identified to ensure confidentiality.

\section{Interviews}

The semi-structured interviews were conducted in the period October 2017-May 2018. We designed interview schedules based on research literature concerning the intersection between unbundling, the introduction of digital technology, and marketisation. The questions operationalised these in terms of the institutional experience, position, and decision-making processes and perceptions of our interviewees on the potentials and perils of unbundled teaching and learning provision in their narrow institutional, and in broader national, and global contexts. Each interview lasted between 45 and $75 \mathrm{~min}$.

\section{Analysis}

All interviews were conducted in English, recorded and transcribed verbatim. Interview transcripts were anonymised and coded with qualitative data analysis software NVivo. The coding framework was developed by research team members, operationalising etic themes from the research literature and unpacking key concepts of marketisation, unbundling and digital education, into smaller analytical categories. We also coded for emic themes drawn directly from interviewees vocabularies rather than the research literature. We intersected themes on decision making and institutional culture of partnering, digital learning, higher education value and mission, and in secondary coding we aligned responses to drivers of change identified through our literature review: (i) PEST/STEEPLE models including Socio-cultural, Technological, Economic, Environmental, Educational/Pedagogic and Politico-legal factors; (ii) internal and external factors; (iii) organisational, cultural and mission-based factors.

\section{Findings}

In this section, we describe the major themes identified from our interviews with senior managers, aligned to, and focused around our research question.

\section{Economic factors are major determinants of online education growth and partnership}

Senior managers talked regularly about growth of online education to generate additional income, alongside the desire to widen access to low income groups. This was put most bluntly by a senior manager at Russell Group University A, who said: "And so public universities are businesses, they are businesses which need to develop a surplus to maintain their buildings, to kind of grow their business like any other businesses. So and there are limited revenue generating opportunities they can come up with, you know. So - and the single biggest revenue generating opportunity is through educating students." A similar approach was taken by senior managers at other universities including post-1992 University X, who told us: "we have had to become, and I think rightly so, much more business-savvy that we can't just sit in these wonderful ivory towers, dishing out wisdom." Yet, at all four universities there was still a strong understanding that profit at public universities was not for profit's sake, but for reinvestment into the core business. As another senior manager at University A put it: "Still, a public 
university to me is, you know, basically where any profit from the university is reinvested back into the university and not into the hands of shareholders.". All interviewees demonstrated their understanding of the delicate balance between universities being perceived as meeting the public good and the need to satisfy economic and societal demands. They may not have referred to 'marketisation' directly, but their focus on income generation as 'business as usual' reveals its presence.

Growth of online learning, especially through full online degrees, is seen as a potential new income stream, and working with OPMs is seen by some universities as a way to achieve this goal. Whilst all universities sampled were involved in the provision of full online degrees via a variety of different mechanisms, they expressed similar motivations to target an audience of professionals who could afford to purchase expensive postgraduate degrees. For example, at University $A$ we were told directly: "our online programmes are focused very much on the full-time professional market who can afford to pay reasonably high postgraduate tuition fees." At University $X$, where the delivery of online degrees is not through partnership with an OPM, they have ambitious predictions about the growth of online student numbers: "we have some fairly firm targets but they're not outrageous but ultimately over the next fifteen years, something like eight or nine thousand students online." This university has clearly made a substantial investment in growth of online education: "we've done it on our own, we've invested hugely, a massive investment from the Board." Recognising the costs of online education development and delivery, this university acknowledges that surplus generation will be a longterm education strategy not driven by short-term profits. All interviewees expressed desire to grow their online populations of learners, with an intention to increase revenue for the university, but had taken different routes to achieve this growth, based on their culture and mission.

\section{Decisions to partner with OPMs are driven by mission and organisational priorities}

Considering the success factors for public universities working in effective partnership with OPMs on online degree programme portfolios, it was clear that alignment of values and culture between the organisations was important for success. This was expressed clearly by a senior manager at University B: "if you have good people managing these partnerships, who really understand and are prepared to work in genuine partnership, rather than keeping to their own very specific party lines, then it works. If you've got people who are very entrenched in their own culture and their own rules and regulations, and perceived quality standards, things can go badly wrong." However, plans to invest in online courses in partnership with OPMs often means taking into account the latter's priorities, which are generally return on investment and marketable courses in subjects such as business, law and health, rather than those that require research infrastructure (e.g. courses in sciences) and subjects without large-scale enrolment potential. This means that universities often have to take more managerial rather than academic decisions: at University $B$ one of the senior managers we interviewed told us: "first of all, there has to be a market for them, so there has to be a fairly sizable market before putting the investment in to develop a new programme. Secondly, it's got to be teachable online. So at the moment, that rules out quite a few things ... if you're going to be running biomedical science laboratories, that's not impossible to do online but 
is very difficult." A senior manager at University A said: "when you're in a revenue share arrangement with a partner, you can't have thirty students a year and expect that the programme is gonna [sic] be successful for both parties." Interestingly, partnership with OPMs appeared to have created a stronger focus on the financial sustainability of degree programmes. At University B, a senior manager described this: "We're much less squeamish about shutting down programmes in the online partnership than across the rest of the university." In the light of this view, another senior manager at University $B$ predicted growth in partnerships between universities and private companies, expanding beyond OPMs and online platform providers: "I think many more partnerships will be entered into. I don't expect that will be in the same way for each institution ... I think there'll be more technology partnerships, more partnerships with employers and government organisations." These universities appear to have accepted that working in partnership with an OPM requires a change of approach, including a more managerial style and financially driven decision making, which may compromise academic mission, and reveals some of the underlying tensions surrounding these decisions.

A senior manager at University $X$ described a number of reasons for their decision to not use an OPM partner, citing data protection issues, institutional pedagogical strategy and institutional risk appetite; but they also saw a clear reason for universities to work with OPMs: "if the institution simply wants to, simply, not simple at all, wants to take courses online for commercial or brand reasons, then the online providers at the traditional [OPM providers] of this world, are a very good solution, because they bring marketing skill and student management skills that perhaps the university wouldn't want to develop." further revealing the different values held by universities and OPMs. At University $Y$, where a previous partnership with an OPM had "failed", a senior manager expressed their views about the value of educational partnerships not just based on financial reward: "I believe in partnership as an academic and well, it has implications in terms of students and student mobility of course. And that's where the financial aspect does come in. But I wouldn't simply go out and do something because it had a bottom line attached to it." Another senior manager at University $Y$ described a partnership with a private company where the relationship has evolved as the university's internal capabilities and capacity has increased: "the initial commitment that we had together has now evolved into a model whereby if we believe they're in the best position to deliver this particular course to these markets, we would use that partner, but obviously we now feel as if we have enough in-house expertise and the ability to run our own courses as well." At this university, the future growth of online education was clearly seen as an in-house activity through a central unit: "we are now kind of a self-contained - we have a distance learning unit and it is their responsibility, predominantly, to take any provision that our schools want to put in online spaces through that unit." These universities have clearly recognised the implications of working in partnership with OPMs for their organisational structures and culture, and have made choices to approach growth in online education through alternative, more internal, means.

\section{Growing online education offers opportunities to deliver institutional mission}

All interviewees talked about growing online education as a means to attract increased numbers of students to their universities, physically and virtually, particularly at the 
postgraduate level. A senior manager at University B said: "the wholly online really is valuable because the students could be working anywhere in the world and they've decided they've come to that point in their career where they want to do something to really boost their career prospects." However, University $B$ also targeted professionals in remote places to widen access and promote positive societal change, and the senior manager we interviewed gave numerous examples of online learners from countries in Africa who had supported local humanitarian situations as a result of learning from online programmes. The benefit of professional learners studying online degrees was emphasised by University B: "35 to 38 is the sort of average age, you get a lot of people who become quite influential in their organisations when they've got this knowledge and this degree". Universities were also using partnerships with online platforms to deliver outputs of externally funded projects. At University $A$, an externally funded project to support refugee education was planning to deliver MOOCs and credit-bearing short courses on an online platform, developed by the same team who create online degrees for OPM partnership activities: "I think the other opportunity from, from digital learning is actually universities being able to deliver education in environments which historically we've not been able to do. So, for example, we're developing programmes to deliver currently pre university education in refugee camps."

Senior managers expressed benefits of growth of online education, including enrichment of the international student experience through use of digital technologies to create online classrooms. A senior manager at University $B$ said: "the international experience of the students has become more and more important ... they're often in a classroom with people from different cultural and geographical backgrounds ... they get a real benefit from working in that genuinely international classroom. So that's a real benefit of wholly online." This same interviewee suggested that the online experience could in some cases exceed that offered on campus: "I could definitely argue that our fully online students get a better experience than if they were doing something similar on campus."

All interviewees talked about how unbundled online education contributed to their mission to offer student-centred, inclusive, flexible learning opportunities to students. At University $X$, where there are plans for a large number of fully online degrees to be delivered on an online platform, students will be able to choose on-campus or online, providing a flexible learning experience: "some students will choose to be on campus, some will choose to be online, but they'll be on the same degree course ... and they may well be working in the same groups, on the same problems." This senior manager expected to see universities realising value from online learning through content being reused and rebundled between on-campus learners and online learners, and learners studying different courses: "No point developing content fifty times across the same institution to do the same basic thing. A piece of marketing in healthcare, a piece of marketing in marketing and a piece of marketing in engineering requires the same basic content, but the way in which I contextualise it is different." The move towards more flexible learning pathways was echoed by a senior manager at University $Y$, who said: "more and more I'm trying to build a flexible environment where students can move between different modes of learning." Looking to the future of universities, senior managers described large changes in the size and shape of universities, predicting large disruptions caused by online education. A senior manager at University B said: "I think 
technology will enable different types of learning, different types of degree. There'll be more on the job learning. There'll be more two year degrees. There'll be more degree apprenticeships. There'll be a lot more university education where you don't attend the campus." Similarly, a senior manager at University $X$ predicted major disruption in the university experience, and suggested that our view of higher education may need to alter: "I very much see, over the next five, ten years, that a student may choose to do a semester on campus, their life changes and they may then choose to do a semester online, or they may choose to do a module on campus and three online, or the other way around, you know ... the technology isn't the problem, it's our conception of what a higher education is that's the real challenge."

However, all interviewees cautioned against excessive unbundling of higher education provision, for example senior manager at University $Y$ who expressed concern about re-use of learning content between different learning journeys: "I can understand from an efficiency game, unbundling looks like a real great opportunity, perhaps, because what you're almost saying is you can create a resource and apply that or deploy that resource and make it available in lots of different contexts ... but it misses out the nuances of the differences of the relationship between the learner and teacher in face-to-face, compared to the learner and teacher in online because the relationship's slightly different." This senior manager at University $Y$ also cautioned against the unbundling of degrees into modular units: "I think what we have to be careful of, as a sector, is we don't fall into the trap of modularising everything because we see that as easier to manage, more efficient or for whatever other reason." This senior manager also stressed the importance of considering the ability of students to be able to 'build their own degree' in an unbundled scenario: "I think the challenge with unbundling is how do you wrap around that context and make it relevant and real? You're requiring a lot of skills from the learner to do that, so they need to understand that they're just going to be delivered the knowledge or the information and the context might not actually be relevant to them, but they're going to have to make the connection for themselves." They went on to make an important distinction between unbundled content and the unbundled experience: "It's easier to unbundle content than it is to unbundle experience because experience is kind of interconnected with the environment that you're in, the city you're in, so the macro and micro environment, you know, the physical space, the digital space they choose to use." This was echoed by a senior manager at University $X$ who stressed the belief that students need universities to navigate the aggregation of learning content into structured learning journeys, noting that fully unbundled provision could be counter-productive: "I still believe students want packages of learning, and that may not be the full degree, but how we package things is important, because I think they absolutely trust us to be the navigators of the learning journey."

\section{Discussion}

This study, utilising a modified form of the PEST model as an analytical tool, has identified a number of drivers influencing senior managers' decision making in relation to growth of online education at English universities. It is clear that universities are operating in a rapidly changing environment in relation to online education. Decision makers are grappling with multiple drivers in relation to campus-based and online education, and identifying mechanisms to generate a return on investment from campus- 
based digital technologies, alongside experimenting with approaches to grow their online education portfolio. As the MOOC market has evolved into a more business-led activity, universities are producing online courses and fully online degrees hoping to attract international students willing to pay high fees (Hill, 2017). However, as the market and educational technology landscape evolves, universities are increasingly faced with a range of options as to how to develop their provision. The findings are important for university decision makers considering options for growth of online education provision, and for effective use of digital technologies on-campus.

In this study, we set out to explore how universities are negotiating the options available to them when embarking on projects to grow online education, in order to understand how their organisational culture and mission impacts on decision-making, in particular decisions to partner with OPMs or online platform providers. We have identified a number of themes from our data, worthy of further discussion, including the role of the market and economic imperatives to increase revenue, and mechanisms to achieve that whilst maintaining the institutional values; the alignment of institutional mission, strategy and culture with that of external organisations, such as OPMs and platform providers; and learner demand for flexible learning opportunities which is challenging the traditional models of university education.

Universities have been negotiating the challenges of marketisation for many years, as articulated clearly by Marginson (2018) and others, and the notion of 'market-making' (Komljenovic \& Robertson, 2016) is evident in our own findings. It is clear from all our respondents that the market as a driver is strong, but universities are not a pure market (Marginson, 2013), which in itself causes tensions. Our interviewees believe that the university has to deliver the public good, whilst also living within its means and generate additional revenue through new mechanisms. Growth of online education is seen as a key method to achieve this. A key question comes in how to achieve that growth, whether through partnership with private companies or by internal investment in skills and resources. For some institutions the choices are limited and external partnerships are the only way to be able to engage in such activity, and in this respect the role of the market is complex and dynamic as Komljenovic and Robertson (2016) suggest. Our data shows (from our limited sample) that Russell Group universities had chosen to work with OPMs, and non-Russell Group universities were using alternative mechanisms. These different approaches derive from their positioning, externally and internally and from their desire to achieve efficiency (Fumasoli et al., 2019). This pattern is borne out by other work we have conducted to map the partnerships between universities and private companies (Swinnerton et al., 2019), which shows that brand and ranking (external) play a significant role in determining the likelihood of partnerships with private companies. The data suggests that when deciding to partner with OPMs, economic imperatives are central, in terms of which subjects to include, the potential size of the cohort and the more likely closure of less financially viable courses (efficiency). Clearly, these universities are able to negotiate a relationship with OPMs which aligns with their institutional values and culture to the satisfaction of their governing bodies (internal), and accept that different styles of management and decision-making will come with that decision. Our interviewees said that these partnerships require involvement of managers and leaders who are willing to make more financially-based decisions (efficiency), perhaps over-riding academic priorities, which could cause 
challenges in some organisations, and one interviewee did refer to academic priorities over the bottom line. It is clear from our data that these factors can be in tension when considering partnering with private companies given their profit-making motivations, which may or may not align with the university's aspirations for additional income, and the expected time scale for return on investment. In the case of OPM partnerships, there will be negotiation required about the portfolio of programmes to be developed as fully online programmes, and the programmes with potential for scale and longterm financial sustainability may not align with the university's expertise, or aspirations for public good, in particular in the aim to widen participation (Gorard et al., 2006). This demonstrates Fumasoli's position about the need for organisational culture to offer a mechanism for a university to mediate the divergence of internal and external drivers when making strategic decisions (Fumasoli et al., 2019). There are risks associated with this approach if senior stakeholders don't have the buy-in or support of academic colleagues when making decisions to partner with private companies to offer academic provision, and signals a further tension between those with strategic responsibilities and those tasked with delivering quality education: this tension could result in friction and lack of engagement which may derail activity, particularly given growing concerns from academics that their knowledge and teaching content is being commercialised (Swartz et al., 2018).

Recently, the predominant mechanism for achieving large-scale growth in online education would have been to partner with an OPM who would invest in marketing and recruitment services. However, as the market for fully online degrees has become more congested, and with increased competition over fees, this has become more challenging. Concurrently, the online platform providers have evolved their business models to include marketing and recruitment services, with the benefit of having large user bases of professional learners on their platforms. Some universities, including one within our sample, has made this move from an OPM partnership to working with an online platform provider, and has ambitious growth plans for fully online learners, taking a longterm educational approach; demonstrating an educational driver dominating economic imperatives. This approach also allows universities to maximise the reuse, repurposing and rebundling of online courses created and delivered on online platforms, and to use these for campus-based learners, and in partnership with other universities, playing to the need for efficiencies. This activity can also reveal tensions between those advocating the 'efficiencies' to be made, as one interviewee stated 'No point developing content fifty times ...', and warnings about quality in relation to making 'it available in lots of different contexts' when online and face to face are different, and partnerships managed by those with different standards of quality.

Alongside the economic and environmental drivers influencing universities choices about how to grow online education, there are also politico-legal and educational drivers to negotiate, particularly in terms of universities role in the public good, widening participation imperatives, and principles about partnerships with profit-making companies (McCowan, 2017). The desire to use digital technology to widen access, as described by Gorard et al. (2006) is present. However, the focus for these managers tends to be on 'the full-time professional market who can afford ... ', rather than the whole breadth of atypical cohorts. Yet, there are examples of universities negotiating these seemingly divergent drivers through innovation, including creating online courses 
for individuals in low income countries, alongside creating high fee professional level fully online degrees. It is also clear that universities are actively considering their approaches to delivering online education, and which partnerships they will foster and grow; our interviewees suggested that partnerships will grow and broaden, and experimentation will continue in this nascent but fertile area.

In terms of campus-based learners, our interviewees all described initiatives to make greater use of digital technology to enhance the student experience, and reflected the need to make use of these technologies to support online learners, and to increase efficiency. Here, educational/pedagogic drivers are in tension with economic drivers, as investments in campus-based digital technologies (e.g. lecture capture) may not deliver clear economic returns (i.e. more students), but may offer income protection (i.e. less students choosing other universities, or leaving). Our data show how universities expect growth in online education, and are preparing for a future where learners demand greater flexibility in the modes of study available to them at undergraduate, postgraduate and professional levels. Whilst our interviewees all acknowledged the future growth in unbundled educational provision, and the benefits this offers in terms of flexibility for learners, they also cautioned around the educational impacts of disaggregating educational content from educational experience, and the crucial role of universities to act as navigators of learning journeys. Our interviewees suggested continued growth in sub-degree qualifications, as alternatives to the traditional 3 year campus-based degree (e.g. micro-credentials, see Oliver, 2019). It is clear that this complex area of activity will continue to evolve, with impacts on many parts of the university, and important decisions will need to made by senior managers about investments in online education. These decisions will need to encompass campus-based and online learners, and be appropriate for the needs of a broader continuum of learners demanding flexibility, value for money and high quality education.

\section{Conclusion}

This study has demonstrated the wide range of drivers influencing decision makers in English universities, when considering the growth of online education. Using a modified form of PEST as an analytical tool has focused on those drivers which most impact decision-making and in doing so has revealed the complex nature of the interdependencies in this terrain. There is a clear expectation that online education will continue to grow, and form part of the core business of universities. It is also clear that universities are trying a range of mechanisms to achieve growth in online education, including partnerships with OPMs, online platform providers and use of in-house capabilities, which is impacting on the type of provision being offered. Our data shows how university senior managers are negotiating a number of drivers which appear to be in conflict, in particular the necessity to drive increased income to the university through online education as a result of restricted funding and lack of physical space, alongside the need to diversify the university population and increase entrants from lower income backgrounds and from developing countries, and the need to pay attention to organisational culture and mission. This drive for increased income to universities may appear to be constraining the aspiration for growth of online education for public good e.g. MOOCs to democratise education or online education to widen 
participation although these drivers are present. That said, universities need a clear strategy to negotiate this terrain effectively.

This study has also demonstrated the potential and limitations of further unbundling of educational provision on online platforms. Whilst unbundling is expected to continue, and may offer flexible learning opportunities for a broader continuum of learners, there are perceived risks to separating educational content from the education experience, and the benefits it brings in terms of context, scaffolding, communities of practice etc. Universities will need to guard against this disaggregation of education, and its unintended consequences, whilst remaining relevant and active in this space, which will continue to attract interest from a wide range of private providers, including employers and new training providers.

\section{Acknowledgements}

The authors are grateful to the participants in the study for sharing their views, and to reviewers of the manuscript.

Authors' contributions

All authors contributed to all aspects of this manuscript. The author(s) read and approved the final manuscript.

\section{Funding}

This research was funded by the National Research Foundation (NRF), South Africa, under grant number 105395 and the Economic and Social Research Council (ESRC), United Kingdom, under grant number ES/P002102/1.

\section{Availability of data and materials}

All data used in this manuscript is available open access at: https://beta.ukdataservice.ac.uk/datacatalogue/studies/ study?id $=853625$

Ethics approval and consent to participate

Ethical clearance and consent was obtained from our own and participants' institutions.

\section{Competing interests}

No potential conflict of interest was reported by the authors.

\section{Author details}

${ }^{1}$ School of Education, University of Leeds, Leeds, UK. ${ }^{2}$ School of Histories, Languages and Cultures, University of Liverpool, Liverpool, UK. ${ }^{3}$ Centre for Innovation in Learning and Teaching, University of Cape Town, Cape Town, South Africa.

Received: 15 April 2020 Accepted: 6 July 2020

Published online: 09 November 2020

\section{References}

Alevizou, G. (2015). From OER to MOOCs: Critical perspectives on the historical mediation trajectories of open education. International Journal of Media and Cultural Politics, 11(2), 203-224.

Baykan, Hümeyra (2017) 'How education should respond to the labour market needs'. Electronic platform for adult learning in Europe. https://ec.europa.eu/epale/en/blog/how-education-should-respond-labour-market-needs (accessed 18 June 2019)

Boden, R., \& Nedeva, M. (2010). Employing discourse: universities and graduate 'employability.'. Journal of Education Policy, 25(1), 37-54. https://doi.org/10.1080/02680930903349489.

Burt, G., Wright, G., Bradfield, R., Cairns, G., \& Van Der Heijden, K. (2014). The role of scenario planning in exploring the environment in view of the limitations of PEST and its derivatives. International Studies of Management \& Organization., 36(3), 50-76. https://doi.org/10.2753/IMO0020-8825360303.

CIPD (2018). PESTLE analysis. CIPD Retrieved from: https://www.cipd.co.uk/knowledge/strategy/organisational-development/ pestle-analysis-factsheet (accessed 20 Feb 2020).

Cliff, A., Walji, A., Mogliacci, R. J., Morris, N. P., \& Ivancheva, M. (2020). Unbundling and higher education curriculum: A culturalhistorical activity theory view of process. Teaching in Higher Education. https://doi.org/10.1080/13562517.2019.1711050.

Coleman, T. E., \& Money, A. G. (2019). Student-centred digital game-based learning: A conceptual framework and survey of the state of the art. Higher Education. https://doi.org/10.1007/s10734-019-00417-0.

Craig, R. (2015). College disrupted: The great unbundling of higher education, (1st ed., ). New York: Palgrave Macmillan Trade.

Croft, N., Dalton, A., \& Grant, M. (2010). Overcoming isolation in distance learning: Building a learning community through time and space. Journal for Education in the Built Environment, 5, 27-64. https://doi.org/10.11120/jebe.2010.05010027.

Deem, R., Hillyard, S., \& Reed, M. I. (2007). Knowledge, higher education, and the new managerialism: The changing management of UK universities. Oxford: Oxford University Press.

Drumm, L. (2019). Folk pedagogies and pseudo-theories: How lecturers rationalise their digital teaching. Research in Learning Technology, 27. https://doi.org/10.25304/rlt.v27.2094.

Englund, C., Olofsson, A. D., \& Price, L. (2018). The influence of sociocultural and structural contexts in academic change and development in higher education. Higher Education, 76, 1051-1069. https://doi.org/10.1007/s10734-018-0254-1. 
Fawcett, T. (2005). Energy use and carbon emission from the higher education sector. Environmental Change Institute, University of Oxford Retrieved from www.ukerc.ac.uk/asset/A6F2C841-4D01-41C4-A97EEAD154BC6741/ (accessed 11 Nov 2018).

Fumasoli, T., Barbato, G., \& Turri, M. (2019). The determinants of university strategic positioning: A reappraisal of the organisation. Higher Education. https://doi.org/10.1007/s10734-019-00481-6.

Galbraith, G. (2018). The 'unbundling' of the university experience - A shot across the bows. In Higher education policy institute Retrieved from https://www.hepi.ac.uk/2018/11/12/6709/ (accessed 13 Nov 2018).

Glance, D. (2014). Online students and "on-campus students learning online" - is there a difference? The conversation. Retrieved from https://theconversation.com/online-students-and-on-campus-students-learning-online-is-there-adifference-25467 (accessed 12 Nov 2018)

Gorard, S., Smith, E., May, H., Thomas, L., Adnett, N., \& Slack, K. (2006). Review of widening participation research: Addressing the barriers to participation in higher education. University of York. Retrieved from http://dera.ioe.ac.uk/6204/1/barriers.pdf. Accessed 10 July 2020.

Hill, P. (2017) MOOCs now focused on paid certificates and OPM market, E-literate, https://mfeldstein.com/moocs-nowfocused-paid-certificates-opm-market/ (accessed 25 Oct 2018)

Jones, C., \& Shao, B. (2011). The net generation and digital natives. Higher Education Academy. Retrieved from https://www. heacademy.ac.uk/system/files/next-generation-and-digital-natives.pdf. (accessed 15 Nov 2018).

Kirkwood, A., \& Price, L. (2016). Technology-enabled learning implementation handbook. Commonwealth of Learning (COL). Retrieved from. http://oasis.col.org/bitstream/handle/11599/2363/2016_TELI-Handbook.pdf? sequence=1\&isAllowed=y. Accessed 10 July 2020.

Komljenovic, J., \& Robertson, S. L. (2016). The dynamics of 'market-making' in higher education. Journal of Education Policy, 31(5), 622-636. https://doi.org/10.1080/02680939.2016.1157732.

Lewis, N. (2015). From unbundling to rebundling: Building a 'more-than-oppositional' politics to university restructuring. Auckland: Retrieved from http://unike.au.dk/events/conference-in-auckland-2015/ (accessed 14 Nov 2018).

Marginson, S. (2013). The impossibility of capitalist markets in higher education. Journal of Education Policy., 28(3), 353-370.

Marginson, S. (2018). Public/private in higher education: A synthesis of economic and political approaches. Studies in Higher Education, 43(2), 322-337. https://doi.org/10.1080/03075079.2016.1168797.

McCowan, T. (2017). Higher education, unbundling, and the end of the university as we know it. Oxford Review of Education, 43(6), 733-748. https://doi.org/10.1080/03054985.2017.1343712.

McIntosh, Rob, (2018). Rethinking the undergraduate business model https://www.timeshighereducation.com/blog/ rethinking-undergraduate-business-model (accessed 25 Oct 2018)

McNay, I. (Ed.) (2005). Beyond mass higher education: Building on experience. Maidenhead \& New York: Society for Research into Higher Education \& Open University Press.

Morris NP, Swinnerton BJ, Hotchkiss S. (2015) Can demographic information predict MOOC learner outcomes?. eMOOCs Conference Proceedings: http://www.emoocs2015.eu/sites/default/files/Papers.pdf (accessed 15 Nov 2018)

Munro, M. (2018). The complicity of digital technologies in the marketisation of UK higher education. International Journal of Educational Technology in Higher Education, 15(1). https://doi.org/10.1186/s41239-018-0093-2.

Oliver, B. (2019) Making micro-credentials work for learners, employers and providers. Retrieved from: http://dteach.deakin. edu.au/microcredentials/ (Accessed 13 Sep 2019)

Redmond, P. (2011). From face-to-face teaching to online teaching: pedagogical transitions. In ASCILITE 2011: 28th annual conference of the Australasian Society for Computers in learning in tertiary education: Changing demands, changing directions, 4-7 Dec 2011, Hobart, Australia.

Robertson, S., \& Komljenovic, J. (2016). Non-state actors, and the advance of frontier higher education markets in the global south. Oxford Review of Education, 42(5), 594-611. https://doi.org/10.1080/03054985.2016.1224302.

Robertson, S. L. (2010). Corporatisation, competitiveness, commercialisation: New logics in the globalising of UK higher education. Globalisation, Societies and Education, 8(2), 191-203. https://doi.org/10.1080/14767721003776320.

Rogers, E. M. (1995). Diffusion of innovations, (4th ed., ). New York: The Free Press.

Sanzgiri, J. 2017. A comparative study of Indian learners in massive open online courses (MOOCs). Presentation at FutureLearn Academic Network, Open University 16th June 2017 https://www.slideshare.net/GO-GN/a-comparativestudy-of-indian-learners-in-massive-open-online-courses-moocs (accessed 13 Nov 2018)

Selwyn, N. (2014). Distrusting educational technology critical questions for changing times. New York: Routledge.

Streckeisen, P. (2018). Neoliberalism in European higher education policy: Economic Nexus and changing patterns of power and inequality. In C. Sin, O. Tavares, S. Cardoso, \& M. J. Rosa (Eds.), European higher education and the internal market, (pp. 47-72). Cham: Springer International Publishing. https://doi.org/10.1007/978-3-319-91881-5_3.

Swartz, R., Ivancheva, M., Morris, N., \& Czerniewicz, L. (2018). Between a rock and a hard place: Dilemmas regarding the purpose of public universities in South Africa. In Higher Education (online first) (accessed 25 Oct 2018).

Swinnerton B, Coop T, Ivancheva M, Czerniewicz L, Morris NP, Swartz R, Walji S, Cliff A. 2019. The Unbundled University: Researching emerging models in an unequal landscape. In: Bonderup Dohn N; Jandric P; Ryberg T; de Laat M (eds.) Mobility, Data and Learner Agency in Networked Learning. Springer: Networked Learning Conference series.

Tomlinson, M. (2018). Conceptions of the value of higher education in a measured market. Higher Education, 75, 711. https:// doi.org/10.1007/s10734-017-0165-6.

UUK (2017). Patterns and trends in higher education in the UK. Universities UK Retrieved from https://www.universitiesuk.ac.uk/ facts-and-stats/data-and-analysis/Documents/patterns-and-trends-2017.pdf (accessed 12 Nov 2018).

Wallhaus, R. A. (2000). E-learning: From institutions to providers, from students to learners. In R. Katz, \& D. Oblinger (Eds.), The ' $E$ ' is for everything: E-commerce, E-business and E-learning in the future of higher education, Educause leadership strategies 2 , (pp. 21-52). San Francisco: Jossey-Bass, Educause \& Price Waterhouse Cooper.

Williamson, B. (2018). Edu-business as usual-Market-making in higher education. Codes in education blog. Retrieved from https://codeactsineducation.wordpress.com/2018/06/21/edu-business-as-usual/

\section{Publisher's Note}

Springer Nature remains neutral with regard to jurisdictional claims in published maps and institutional affiliations. 